\title{
Treatment and Survival of Medicare Beneficiaries with Colorectal Cancer: A Comparative Analysis Between a Rural State Cancer Registry and National Data
}

\author{
Pallavi. B. Rane, PhD, S. Suresh Madhavan, $\mathrm{PhD}^{2}$, Usha Sambamoorthi, $\mathrm{PhD}$, \\ Kalidindi Sita, MS, Sobha Kurian, $\mathrm{MD}^{3}$, and Xiaoyun Pan, $\mathrm{PhD}^{4}$
}

\begin{abstract}
The aim was to examine and compare with "national" estimates, receipt of colorectal cancer (CRC) treatment in the initial phase of care and survival following a CRC diagnosis in rural Medicare beneficiaries. A retrospective study was conducted on fee-for-service Medicare beneficiaries diagnosed with CRC in 2003-2006, identified from West Virginia Cancer Registry (WVCR)-Medicare linked database $(\mathrm{N}=2119)$. A comparative cohort was identified from Surveillance, Epidemiology, and End Results (SEER)-Medicare $(\mathrm{N}=38,168)$. CRC treatment received was ascertained from beneficiaries' Medicare claims in the 12 months post CRC diagnosis or until death, whichever happened first. Receipt of minimally appropriate CRC treatment (MACT) was defined using recommended CRC treatment guidelines. All-cause and CRC-specific mortality in the 36-month period post CRC diagnosis were examined. Differences in usage of CRC surgery, chemotherapy, and radiation were observed between the 2 populations, with those from WVCR-Medicare being less likely to receive any type of CRC surgery (adjusted odds ratio $[\mathrm{AOR}]=0.82 ; 95 \%$ confidence interval $[\mathrm{CI}]=[0.73-0.93]$ ). Overall, those from WVCRMedicare had a lower likelihood of receiving MACT, $(\mathrm{AOR}=0.85 ; 95 \% \mathrm{CI}=[0.76-0.96])$ compared to their national counterparts. Higher hazard of CRC mortality was observed in the WVCR-Medicare cohort (adjusted hazard ratio $=1.26 ; 95 \% \mathrm{CI}=[1.20-1.32]$ ) compared to the SEER-Medicare cohort. Although more beneficiaries from WVCR-Medicare were diagnosed in early-stage CRC compared to their SEER-Medicare counterparts, they had a lower likelihood of receiving MACT and a higher hazard of CRC mortality. This study highlights the need for an increased focus on improving access to care at every phase of the CRC care continuum, especially for those from rural settings.
\end{abstract}

\section{Introduction}

C Olorectal cancer (CRC) Is the third most commonly diagnosed cancer and the third leading cause of cancer deaths in both men and women in the United States, with an estimated 50,830 deaths related to CRC in the year 2013. ${ }^{1}$ West Virginia (WV), which is one of the most rural states in the nation, had the highest mortality rate for CRC at 20.0, 95\% $\mathrm{CI}=[19.1-20.8]$ compared to the national average of $15.7,95 \% \mathrm{CI}=[15.6-15.9]$ in 2009 , according to the most recent statistics from the US cancer statistics working group (rates per 100,000 men and women, age-adjusted to the 2000 US standard population). ${ }^{2}$
There is strong evidence that early detection and receipt of appropriate treatment can help lower mortality from CRC. ${ }^{3}$ However, management of CRC may require specialized care including medical, surgical, radiation, and oncology services, which often are not easily accessible to those from rural areas and to those having low socioeconomic status. ${ }^{4-8}$ It has been found that CRC patients from rural areas frequently travel long distances to receive cancer care, and that medical and radiation oncology are some of the services that are less accessible to them. ${ }^{4}$ Low socioeconomic status also is found to be associated with receipt of less aggressive treatment and with an increased risk of mortality among CRC patients. ${ }^{5}$

\footnotetext{
${ }^{1}$ Center for the Evaluation of Value and Risk in Health, Tufts Medical Center Institute for Clinical Research and Health Policy Studies, Boston, MA.

${ }^{2}$ Department of Pharmaceutical Systems and Policy, School of Pharmacy, West Virginia University, Morgantown, WV.

${ }^{3}$ Department of Radiology Hematology/Oncology, Mary Babb Randolph Cancer Center, West Virginia University, Morgantown, WV. ${ }^{4}$ Evidera, Lexington, MA.
} 
$\mathrm{WV}$ is among the states in the nation with the lowest median household income levels, with nearly $17.5 \%$ of its residents living below the poverty line, ${ }^{9}$ and with a population that is aging and medically underserved. ${ }^{10}$ Additionally, WV is among the top-ranking states in the nation for high morbidity and mortality related to other cancers, heart diseases, stroke, and diabetes. ${ }^{11}$ With its rurality, there may be a general lack of access to health care in WV. This may result in lack of receipt of appropriate CRC care and possibly lead to the high CRC mortality in a rural state such as WV. Other factors such as low socioeconomic status and the increased morbidity related to other chronic conditions among West Virginians also may contribute to the high CRC mortality in the state. Furthermore, there is a paucity of studies on the receipt of guidelinerecommended, minimally-appropriate CRC treatment (MACT) and survivorship in such an elderly population, which is probably sicker and lives in rural and medically underserved areas. Thus, this retrospective cohort study was conducted to examine the receipt of guideline-recommended MACT among the elderly with CRC from a rural setting such as WV, and whether or not the treatment received explained the excess mortality in the state after controlling for the other factors. Data from the WV Cancer Registry (WVCR)-Medicare linked data set were used. The likelihood of receiving MACT and the excess CRC mortality were further examined by doing a comparative analysis of WVCR-Medicare data with estimates derived from the Surveillance, Epidemiology, and End Results (SEER)-Medicare data, which served as "national" comparators. The WVCR was not a part of the national SEERMedicare data. Fee-for-service (FFS) beneficiaries from the 2 populations were compared with respect to: $(a)$ the type of CRC treatment received, $(b)$ the extent of receipt of MACT, (c) factors associated with receipt of MACT, and $(d)$ the associated survival in the 3 -year period following a CRC diagnosis. Treatment received in the initial phase of care (defined as the 12-month period starting from the date of diagnosis) following a CRC diagnosis was examined.

\section{Methods}

\section{Data sources}

Beneficiaries diagnosed with CRC were identified from the statewide WVCR-Medicare and the national SEERMedicare linked data set. The WVCR, established in 1991 by the WV Department of Health and Human Resources (WVDHHS), collects data on all cancer cases diagnosed and/or treated in the state of WV. The WVCR data provide information on demographics, cancer-related variables (primary site, tumor grade, date, and stage of diagnosis), and date and cause of mortality for those present in the registry. The completely de-identified linked WVCR-Medicare data set was developed at West Virginia University (WVU) through collaborative agreements with multiple agencies including the WVCR, WVDHHS, and the Centers for Medicare \& Medicaid Services (CMS). A detailed description of the WVCR-Medicare linked data set and the linkage process can be found elsewhere. ${ }^{12}$ The Medicare component of the linked data set provided information on the beneficiaries' Medicare enrollment eligibility (health maintenance organization (HMO)-enrollment, Part A and/or Part B eligibility), demographics, dates and claims of services used, and amounts billed and paid for services used by individuals aged $\geq 65$ years, who were provided health insurance through Medicare. Information on claims from the inpatient, outpatient, physician, home health agencies, hospice care, and durable medical equipment is available.

The SEER-Medicare linked data set was a result of the collaborative efforts of the National Cancer Institute (NCI), the SEER program, and CMS. The SEER program collects information on newly diagnosed cases of cancer from several population-based tumor registries across the United States. The number of registries included and the area covered by SEER has been expanding over time, and these tumor registries are from geographically defined areas that currently represent approximately $28 \%$ of the US population. ${ }^{13}$ For the current study, SEER data spanning the period 2003-2006 were used, which included data from only 13 registries. The SEER-Medicare data set provided clinical (diagnosis information for up to 10 different incident cancer cases), demographic, and mortality data for individuals diagnosed with cancer, and data from their Medicare claims (all health care services used and covered by Medicare from the time of the individual's Medicare eligibility until death). A detailed description of the data linkage process and the linked SEER-Medicare data can be found elsewhere. ${ }^{14}$ This registry data study followed the regulations and was approved by the WVU Institutional Review Board.

\section{Patient selection}

Elderly FFS Medicare beneficiaries aged $\geq 66$ years and diagnosed with CRC in 2003-2006 were identified from WVCR-Medicare data using the International Classification of Diseases for Oncology, Third Rrevision (ICD-O-3) site codes C18.0-C18.9, C19.9, and C20.9. The index period for CRC diagnosis was limited to only between 2003-2006 to allow for a 36-month follow-up period after the index date, and also because of limited availability of the WVCRMedicare linked data set for the period after 2009 at the time of study completion. CRC cases in the comparison SEERMedicare cohort also were identified for the same period using the SEER cancer site recode variable coded as 15-23, and 25-26. The age of 66 years was selected to allow for at least a year of Medicare eligibility prior to cancer diagnosis, and to capture claims for chronic conditions in the 12-month pre-diagnosis period for the beneficiaries. The index date for each beneficiary was defined as the date of his/her CRC diagnosis. Beneficiaries who were enrolled in MedicareHMO, or those who were not eligible for Part A and/or Part B Medicare benefits during the observation period (ie, at any time during the 12-month pre-index date period to the end of their follow-up) were excluded from the study population. Finally, beneficiaries with multiple primary cancer diagnoses, those diagnosed with CRC through autopsy or death certificate review, and those with unstaged/unknown stage CRC diagnosis also were excluded.

\section{Study variables}

The dependent variables in the current study were treatment in the initial phase of care including a 5-category CRC treatment type variable (categorized as surgery only, chemotherapy and/or radiation therapy only, surgery + adjuvant chemotherapy or radiation therapy, surgery + chemoradiation, and no treatment received), and a dichotomous 
variable for receipt of MACT (appropriate treatment, and no appropriate treatment). CRC-specific and all-cause mortality also were evaluated.

The treatment received in the initial phase of CRC care was examined, during which the costs for cancer care were found to be the highest in phase of care models used in previous cancer studies. To capture this, beneficiaries were followed for up to a period of 12 months from their index date or until death, whichever happened first. The initial phase of care definition was based on previously published studies. ${ }^{15-17}$ Treatment received was ascertained from Medicare claims using a combination of the International Classification of Diseases, Ninth Revisions, Clinical Modification (ICD-9-CM) diagnosis and procedure, current procedural terminology, health care common procedure coding system, and diagnosis-related group codes (listed in online Supplementary Table 1, available in the online article at www.liebertpub.com/pop). Using the above information on the treatment received, receipt of MACT was then defined based on the National Comprehensive Cancer Network and NCI guidelines for treatment of cancers of the colon and rectum, which vary by cancer stage and site (see online Supplementary Table 2). ${ }^{18,}{ }^{19}$ To evaluate treatmentassociated survival, beneficiaries were followed for up to 36 months from their index date or until death, whichever happened first. For all-cause mortality analyses, beneficiaries who were alive at the end of follow-up were censored; and for CRC-specific mortality, those who died of causes other than CRC and those who were alive at the end of follow-up were censored. The date and cause of death information used to examine all-cause and CRC-specific mortality were derived from the Medicare component of the linked data sets.

The independent variables comprised the patient characteristics, clinical characteristics including cancer-related and comorbidity burden variables, and the total number of office visits. Beneficiaries were classified into 4 age groups (66$70 ; 71-75 ; 76-80$; and $>80$ years), 2 race categories (whites versus others, as $97 \%$ of the WV population is white), 2 sex categories, and 2 categories for area of residence (metropolitan areas versus other areas). They also were classified into 3 groups based on their census tract median household income $(<\$ 35,000 ; \$ 35,001$ to $\$ 45,000$; and $>\$ 45,000)$. Beneficiaries were further classified into 3 groups based on their cancer stage at diagnosis (categorized as in situ or localized, regional, or distant stage), and cancer site (colon or rectum). For the purpose of statistical analysis in the current study, those with in situ and localized stages were combined because of the small cell sizes of beneficiaries in these stages stratified by treatment type for the WVCRMedicare cohort. The overall comorbidity burden for each beneficiary also was assessed based on preexisting conditions diagnosed in the 12-month pre-index period. Identification of chronic conditions was made using ICD-9-CM diagnoses codes and an algorithm to increase the specificity of the selection of chronic conditions. This algorithm has been used in prior studies, and involved checking for the presence of at least 1 inpatient or 2 outpatient claims related to each comorbid condition from the Medicare files. ${ }^{20}$ The Deyo-Charlson comorbidity index (CCI) scores were then derived after identifying these chronic conditions. Cancerrelated comorbidities were excluded while deriving these
CCI scores, which were then used to categorize the beneficiaries into 3 groups $(\mathrm{CCI}=0,1-2$, and $\geq 3)$. Beneficiaries also were classified based on the total number of office visits they had in the pre-index 12-month period, categorized into quintiles. The total number of office visits served as a proxy measure of the beneficiaries' contact with the health care system.

\section{Statistical analysis}

The patient and clinical characteristics and other variables for the 2 cohorts were compared using overall chi-square tests. Then, the proportion of beneficiaries receiving treatment in the 5 categories and those receiving MACT for both the WVCR-Medicare and SEER-Medicare cohorts were examined. Significant differences in treatment rates between beneficiaries in different subgroups were tested using overall chi-square tests. Multivariable logistic regression was used to examine the odds of receiving any surgery, chemotherapy, or radiation as a part of the treatment modality, and also the odds of receipt of MACT. In the regression models, beneficiaries from both the WVCRMedicare and SEER-Medicare cohorts were combined, where beneficiaries from the SEER-Medicare cohort served as the reference group. Independent covariates in the regression models for treatment type included age, sex, race/ ethnicity, cancer site, stage at diagnosis, CCI score, number of office visits, metropolitan status, and median household income. The independent covariates in the logistic regressions for MACT included all of the aforementioned variables, except for cancer site and stage at diagnosis. Additional regression models were further conducted on the combined population to predict the receipt of MACT, stratified by cancer site and stage at diagnosis. Lastly, Cox proportional hazards models were used to examine the association between the receipt of CRC treatment and allcause and CRC-specific mortality after controlling for all of the aforementioned covariates. While conducting survival analysis, weights that were the inverse probability of receiving treatment (IPTW) also were used to account for selection bias, similar to approaches used in prior cancer epidemiological studies. ${ }^{21-23}$ All analyses in the current study were conducted using SAS, version 9.3 (SAS Institute Inc., Cary, NC).

\section{Results}

\section{Population characteristics}

The descriptions of the study population of 2119 and 38,168 FFS Medicare beneficiaries with CRC identified from WVCR-Medicare and SEER-Medicare (hereafter referred to as the national cohort), respectively, are summarized in Table 1. Statistically significant differences were observed between the 2 cohorts in most characteristics. Beneficiaries with CRC from WVCR-Medicare were younger, predominantly white, and comprised fewer females compared to the national population. Fewer beneficiaries from WVCR-Medicare were diagnosed at regional and distant-stage CRC as compared to the national cohort. Those from WVCR-Medicare had a higher comorbidity burden, and a higher proportion of them lived in nonmetropolitan areas. Also, only $8 \%$ of those from the 
Table 1. Description of the Study Cohorts, WVCR-MEdicare AND SEER-MEDICARE (2003-2006)

\begin{tabular}{|c|c|c|c|c|c|}
\hline \multirow[b]{2}{*}{ Characteristics } & \multicolumn{2}{|c|}{$\begin{array}{l}\text { WVCR- } \\
\text { Medicare }\end{array}$} & \multicolumn{2}{|c|}{$\begin{array}{l}\text { SEER- } \\
\text { Medicare }\end{array}$} & \multirow[b]{2}{*}{ Sig } \\
\hline & $\begin{array}{c}N \\
2119\end{array}$ & $\begin{array}{c}\% \\
100\end{array}$ & $\begin{array}{c}N \\
38,168\end{array}$ & $\begin{array}{c}\% \\
100\end{array}$ & \\
\hline Age group & & & & & $* * *$ \\
\hline $66-70$ & 469 & 22.1 & 7415 & 19.4 & \\
\hline $71-75$ & 519 & 24.5 & 8258 & 21.6 & \\
\hline $76-80$ & 513 & 24.2 & 8752 & 22.9 & \\
\hline$>80$ & 618 & 29.2 & 13,743 & 36.0 & \\
\hline Sex & & & & & $* *$ \\
\hline Male & 1018 & 48.0 & 16,948 & 44.4 & \\
\hline Female & 1101 & 52.0 & 21,220 & 55.6 & \\
\hline Race & & & & & $* * *$ \\
\hline White & 2064 & 97.4 & 32,552 & 85.3 & \\
\hline Other & 55 & 2.6 & 5616 & 14.7 & \\
\hline \multicolumn{6}{|l|}{ Cancer site } \\
\hline Colon & 1592 & 75.1 & 29,240 & 76.6 & \\
\hline Rectal & 527 & 24.9 & 8928 & 23.4 & \\
\hline Stage at diagnosis & & & & & $* *$ \\
\hline In situ/localized & 1056 & 49.8 & 17,758 & 46.5 & \\
\hline Regional & 705 & 33.3 & 13,309 & 34.9 & \\
\hline Distant & 358 & 16.9 & 7101 & 18.6 & \\
\hline \multicolumn{5}{|l|}{$\begin{array}{l}\text { Charlson comorbidity } \\
\text { index score }\end{array}$} & $* * *$ \\
\hline zero & 870 & 41.1 & 18,494 & 48.5 & \\
\hline 1 or 2 & 1021 & 48.2 & 16,498 & 43.2 & \\
\hline$\geq 3$ & 228 & 10.8 & 3176 & 8.3 & \\
\hline \multicolumn{6}{|l|}{ Office visits } \\
\hline Quintile 1 & 403 & 19.0 & 7390 & 19.4 & \\
\hline Quintile 2 & 437 & 20.6 & 7526 & 19.7 & \\
\hline Quintile 3 & 452 & 21.3 & 8561 & 22.4 & \\
\hline Quintile 4 & 434 & 20.5 & 7254 & 19.0 & \\
\hline Quintile 5 & 393 & 18.5 & 7437 & 19.5 & \\
\hline Vital status & & & & & $*$ \\
\hline Alive & 1184 & 55.9 & 20,426 & 53.5 & \\
\hline Dead & 935 & 44.1 & 17,742 & 46.5 & \\
\hline Metropolitan status & & & & & $* * *$ \\
\hline Metro & 1037 & 48.9 & 31,979 & 83.8 & \\
\hline Nonmetro & 1082 & 51.1 & 6189 & 16.2 & \\
\hline $\begin{array}{l}\text { Median household } \\
\text { income }\end{array}$ & & & & & $* * *$ \\
\hline$\leq \$ 35,000$ & 784 & 37.2 & 10,047 & 26.3 & \\
\hline$\$ 36,000-\$ 45,000$ & 1153 & 54.7 & 8576 & 22.5 & \\
\hline$>\$ 46,000$ & 169 & 8.0 & 19,545 & 51.2 & \\
\hline
\end{tabular}

Note: Based on 2119 elderly Medicare beneficiaries with CRC identified from the linked West Virginia Cancer Registry (WCVR)Medicare data and 38,168 beneficiaries identified from the SEERMedicare data. ${ }^{1}$ Modified Charlson comorbidity index: Deyo-Charlson comorbidity scores, which were calculated for the pre-index 12-month period for each beneficiary and excluded cancer-related comorbidities. Asterisks represent significant group differences by the data source/ population using chi-square test. $* * * P<.001 ; * * .001 \leq P<.01 ; * .01 \leq$ $P<.05$.

$\mathrm{CRC}=$ colorectal cancer; $\mathrm{SEER}=$ Surveillance, Epidemiology, and End Results.

WVCR-Medicare cohort had a median household income of $\geq \$ 46,000$ compared to $51.2 \%$ of those in the national cohort. No statistically significant differences were observed between the 2 cohorts for characteristics such as cancer site and the total number of office visits.

\section{Distribution of CRC treatment}

The proportions of beneficiaries receiving the different types/combinations of CRC treatments (classified in the 5 patterns already described, and by cancer type and stage at diagnosis) were examined and compared between the 2 cohorts as described in Table 2. The proportions of beneficiaries across the different treatment patterns were consistently smaller for those from WVCR-Medicare as compared to the national cohort. Not surprisingly, these proportions were higher for those from WVCR-Medicare in the "No treatment" category for both the cancer sites and stage at diagnosis subgroups. Later, separate logistic regressions were conducted on the combined population to determine the likelihood of receiving any type of CRC surgery, chemotherapy, and radiation therapy. The national cohort served as the reference group in these regressions, the results of which are summarized in Table 3. Beneficiaries from the WVCR-Medicare cohort were less likely to receive any type of CRC surgery as part of their treatment (adjusted odds ratio $[\mathrm{AOR}]=0.82 ; 95 \% \mathrm{CI}=[0.73-0.93])$. The factors associated with a lower likelihood of receiving any type of surgery included progressing age, being male, belonging to a nonwhite race, having rectal cancer, being diagnosed at distant-stage CRC, having a higher comorbidity burden, and having fewer physician office visits. Beneficiaries from the WVCR-Medicare cohort were as likely as those from the national cohort to receive any chemotherapy as a part of their treatment modality $(\mathrm{AOR}=1.05 ; 95 \% \mathrm{CI}=[0.78$ 1.33]). However, they were $25 \%$ more likely than their national counterparts to receive radiation therapy. The factors associated with a higher likelihood of receiving radiation therapy included younger age, being male, having rectal cancer, CRC diagnoses at later stages, and having a lower comorbidity burden.

\section{Guideline-recommended appropriate CRC treatment}

Table 4 summarizes subgroup differences (both adjusted and unadjusted) in receipt of MACT between the 2 cohorts. Descriptive analysis showed that, overall, Medicare beneficiaries with CRC from the WVCR-Medicare cohort were less likely to receive MACT compared to beneficiaries from the national cohort $(81.83 \%$ vs $83.98 \%)$. This overall difference was found to be statistically significant. Additionally, statistically significant differences in receipt of MACT were observed in some subgroups: males, whites, those with colon cancer, those with CRC diagnosed at regional stage, those with CCI score of zero, those who belonged to the first and the second quintile groups of total number of physician visits, those who were alive, and those who lived in metropolitan areas. In all these subgroups, fewer beneficiaries from WVCR-Medicare received MACT compared to their counterparts in the national cohort.

The factors associated with receipt of MACT in the combined population (where the 2 study populations were combined and the national cohort served as a reference group in a multivariable logistic regression model) are as summarized in Table 4. Overall, the beneficiaries from WVCR-Medicare were $15 \%$ less likely to receive MACT compared to their national cohort counterparts $(\mathrm{AOR}=0.85 ; 95 \% \mathrm{CI}=[0.76-0.96])$. Regression models stratified by cancer site and stage at diagnosis also were conducted on the combined population to determine 
Table 2. Percentage of Colorectal Cancer Treatments by Cancer Type and Stage at Diagnosis among Elderly Medicare Beneficiaries, WVCR-Medicare and SEER-Medicare Cohorts (2003-2006)

\begin{tabular}{|c|c|c|c|c|c|}
\hline \multirow[b]{2}{*}{ Treatment type } & \multirow[b]{2}{*}{ Stage at diagnosis } & \multicolumn{2}{|c|}{ Colon cancer } & \multicolumn{2}{|c|}{ Rectal cancer } \\
\hline & & WVCR Medicare & SEER Medicare & WVCR Medicare & SEER Medicare \\
\hline \multicolumn{6}{|l|}{ Surgery only } \\
\hline & In situ/localized & 76.69 & 79.26 & 36.46 & 42.83 \\
\hline & Regional & 52.51 & 56.99 & 24.49 & 27.34 \\
\hline & Distant & 30.83 & 33.18 & 17.39 & 19.50 \\
\hline \multicolumn{6}{|c|}{ Chemo and/or rad only } \\
\hline & In situ/localized & 0.65 & 0.50 & 18.75 & 11.75 \\
\hline & Regional & 1.08 & 0.74 & 22.45 & 18.27 \\
\hline & Distant & 9.40 & 9.14 & 29.35 & 28.06 \\
\hline \multicolumn{6}{|c|}{ Surgery + adj therapy } \\
\hline & In situ/localized & 6.64 & 6.22 & 6.60 & 6.41 \\
\hline & Regional & 39.25 & 38.52 & 17.69 & 18.24 \\
\hline & Distant & 31.95 & 31.20 & 18.48 & 22.66 \\
\hline \multicolumn{6}{|c|}{ Surgery + chemo-radiation } \\
\hline & In situ/localized & 0.52 & 0.38 & 11.46 & 9.45 \\
\hline & Regional & 1.97 & 1.55 & 27.21 & 29.33 \\
\hline & Distant & 3.38 & 2.38 & 7.61 & 9.35 \\
\hline \multicolumn{6}{|l|}{ No treatment } \\
\hline & In situ/localized & 15.49 & 13.64 & 26.74 & 29.57 \\
\hline & Regional & 5.20 & 2.21 & 8.16 & 6.83 \\
\hline & Distant & 24.44 & 24.09 & 27.17 & 20.43 \\
\hline
\end{tabular}

Note: Based on 2119 elderly Medicare beneficiaries with CRC identified from the linked West Virginia Cancer Registry (WVCR)Medicare data and 38,168 beneficiaries identified from the SEER-Medicare data. Numbers represent percentages in each category.

$\mathrm{CRC}=$ colorectal cancer; SEER $=$ Surveillance, Epidemiology, and End Results.

if such differences existed between WVCR-Medicare and the national cohort beneficiaries specifically within these subgroups (Figure 1). Statistically significant differences were observed between the beneficiaries from WVCR-Medicare and the national cohort only for those diagnosed with regional stage CRC $(\mathrm{AOR}=0.74 ; 95 \% \mathrm{CI}=[0.56-0.98])$ and those who had colon cancer $(\mathrm{AOR}=0.81 ; 95 \% \mathrm{CI}=[0.70-0.94])$. Beneficiaries from WVCR-Medicare were less likely to receive MACT compared to their national counterparts in both these subgroups.

\section{All-cause and CRC-specific mortality}

Several regression models were conducted to examine both CRC-specific and all-cause mortality. The results of the model using the combined population, where beneficiaries from the national cohort served as the reference group are summarized in Table 5. CRC-specific mortality was found to be associated with age, sex, stage at diagnosis, number of office visits, and treatment patterns, after applying the IPTW and controlling for all important covariates. The relative risk for CRC-specific mortality (adjusted hazards ratio [AHR $]=1.26 ; 95 \% \mathrm{CI}=[1.20-1.32]$ ) was high for those from the WVCR-Medicare compared to those in the national cohort. In another regression model using the combined population, the beneficial effect of receiving MACT was evident from the overall reduced $\mathrm{CRC}$-specific mortality $(\mathrm{AHR}=0.60 ; 95 \% \mathrm{CI}=[0.59-0.61])$ among those who received appropriate treatment compared to those who did not. There was no significant difference between the 2 cohorts with respect to relative risk for all-cause mortality.

Regressions also were conducted to model the risk of CRC-specific mortality for beneficiaries from the WVCR-
Medicare and the national cohorts separately. (Data not shown.) Females and older beneficiaries were at a higher risk of CRC-specific mortality. Those diagnosed at regional and distant stages had higher CRC-specific mortality compared to those diagnosed at in situ/localized stages. Beneficiaries who had a higher number of office visits were more likely to experience CRC-specific mortality compared to those who had fewer visits. Metropolitan status was associated with CRC-specific mortality only for those from WVCR-Medicare, with those from nonmetropolitan areas having a $34 \%$ greater hazard of CRC-specific mortality compared to those from metropolitan areas $(\mathrm{AHR}=1.34$; $95 \% \mathrm{CI}=[1.18-1.52])$.

\section{Discussion}

As stated earlier, WV is one of the most rural states in the nation, and had the highest mortality rate for CRC in 2009. This study provides a comparative analysis between elderly FFS Medicare beneficiaries diagnosed with CRC identified from the WVCR-Medicare and SEER-Medicare linked data sets. The latter served as a proxy for a national comparison in the absence of an actual national linked data set. CRC treatment patterns, extent of receipt of MACT, and the associated survival in the 2 study cohorts were systematically examined. The study results indicated that the populations from the 2 cohorts were statistically different in terms of most of their characteristics. Furthermore, the study results show that although a high proportion of beneficiaries in WVCR-Medicare had early-stage CRC (when it can still be treated effectively) compared to their national counterparts in the SEER-Medicare cohort, they had poorer CRC 
Table 3. Receipt of Surgery, Chemotherapy, and Radiation Therapy among Elderly Medicare Beneficiaries With CRC From WVCR-Medicare and SEER-Medicare Cohorts (2003-2006)

\begin{tabular}{|c|c|c|c|c|c|c|c|c|c|}
\hline & & Adjusted oc & ratio & AORs) & m logistic reg & sion & & & \\
\hline & & rgery for $C R$ & & & otherapy for & & & diation for $C$ & \\
\hline & $A O R$ & $95 \% C I$ & Sig & $A O R$ & $95 \% C I$ & Sig & $A O R$ & $95 \% C I$ & Sig \\
\hline Population & & & & & & & & & \\
\hline SEER-Medicare & Ref & & & Ref & & & Ref & & \\
\hline WVCR-Medicare & 0.82 & {$[0.73-0.93]$} & $* *$ & 1.05 & {$[0.78-1.33]$} & & 1.25 & [1.06-1.48] & $* *$ \\
\hline Age-group & & & & & & & & & \\
\hline $66-70$ years & Ref & & & Ref & & & Ref & & \\
\hline $71-75$ years & 1.11 & [1.02-1.20] & $*$ & 0.79 & {$[1.32-2.25]$} & $* * *$ & 0.89 & [0.80-0.99] & $*$ \\
\hline $76-80$ years & 1.09 & [1.01-1.19] & $*$ & 0.53 & [1.04-1.71] & $*$ & 0.80 & {$[0.72-0.89]$} & $* * *$ \\
\hline$>80$ years & 0.88 & {$[0.82-0.95]$} & $* *$ & 0.16 & {$[0.62-1.08]$} & & 0.43 & {$[0.39-0.48]$} & $* * *$ \\
\hline Sex & & & & & & & & & \\
\hline Male & Ref & & & Ref & & & Ref & & \\
\hline Female & 1.20 & [1.14-1.27] & $* * *$ & 0.86 & {$[0.84-1.57]$} & & 0.88 & [0.82-0.96] & $* *$ \\
\hline Race & & & & & & & & & \\
\hline White & Ref & & & Ref & & & Ref & & \\
\hline Other & 0.84 & {$[0.77-0.90]$} & $* * *$ & 0.90 & [0.84-0.97] & $* *$ & 0.86 & [0.77-0.97] & $*$ \\
\hline Cancer site & & & & & & & & & \\
\hline Colon & 4.15 & [3.92-4.39] & $* * *$ & 0.48 & {$[0.45-0.50]$} & $* * *$ & 0.04 & {$[0.03-0.04]$} & $* * *$ \\
\hline Rectal & Ref & & & Ref & & & Ref & & \\
\hline Stage at diagnosis & & & & & & & & & \\
\hline In situ/localized & Ref & & & Ref & & & Ref & & \\
\hline Regional & 3.18 & [2.95-3.41] & $* * *$ & 9.21 & [8.65-9.80] & $* * *$ & 2.90 & [2.65-3.16] & $* * *$ \\
\hline Distant & 0.41 & {$[0.39-0.44]$} & $* * *$ & 8.99 & [8.37-9.66] & $* * *$ & 2.08 & [1.87-2.32] & $* * *$ \\
\hline Charlson comorbidit & ndex s & & & & & & & & \\
\hline Zero & Ref & & & Ref & & & Ref & & \\
\hline 1 or 2 & 0.92 & [0.87-0.97] & $* *$ & 0.84 & {$[0.79-0.89]$} & $* * *$ & 0.98 & [0.90-1.06] & \\
\hline$\geq 3$ & 0.89 & {$[0.80-0.99]$} & $*$ & 0.57 & {$[0.51-0.64]$} & $* * *$ & 0.84 & [0.71-1.00] & $*$ \\
\hline Office visits & & & & & & & & & \\
\hline Quintile 1 & Ref & & & Ref & & & Ref & & \\
\hline Quintile 2 & 1.31 & [1.20-1.42] & $* * *$ & 1.19 & [1.10-1.29] & $* * *$ & 0.98 & [0.87-1.10] & \\
\hline Quintile 3 & 1.36 & {$[1.25-1.48]$} & $* * *$ & 1.15 & [1.06-1.24] & $* * *$ & 0.97 & [0.87-1.09] & \\
\hline Quintile 4 & 1.43 & [1.31-1.56] & $* * *$ & 1.10 & [1.01-1.20] & $*$ & 0.92 & [0.81-1.05] & \\
\hline Quintile 5 & 1.44 & [1.31-1.58] & $* * *$ & 1.00 & {$[0.92-1.10]$} & & 0.76 & {$[0.66-0.87]$} & $* * *$ \\
\hline Metropolitan status & & & & & & & & & \\
\hline Metro & Ref & & & Ref & & & Ref & & \\
\hline Nonmetro & 0.97 & [0.90-1.05] & & 0.96 & [0.89-1.03] & & 1.04 & [0.93-1.16] & \\
\hline Median household in & me & & & & & & & & \\
\hline$\leq \$ 35,000$ & Ref & & & Ref & & & Ref & & \\
\hline$\$ 36,000-45,000$ & 1.03 & [0.95-1.11] & & 1.11 & [1.04-1.20] & $* *$ & 0.94 & [0.84-1.05] & \\
\hline$>\$ 46,000$ & 1.06 & [0.99-1.14] & & 1.21 & [1.13-1.30] & $* * *$ & 0.98 & [0.88-1.08] & \\
\hline
\end{tabular}

Note: Based on 2119 elderly Medicare beneficiaries with CRC identified from the linked West Virginia Cancer Registry (WCVR)Medicare data and 38,168 beneficiaries identified from the SEER-Medicare data. Asterisks represent significant AOR. $* * * P<.001 ; * * .001$ $<P<.01 ; * .01<P<.05$. The logistic regression controlled for age, sex, race, cancer site and stage, Charlson comorbidity index, number of office visits, metro status, median household income, and the data source/population as independent variables.

$\mathrm{CRC}=$ colorectal cancer; SEER $=$ Surveillance, Epidemiology, and End Results.

survivorship. This poorer survivorship may be related to a lower likelihood of receiving MACT in beneficiaries from WVCR-Medicare compared to those in the national cohort, which was observed in the study results.

The beneficiaries with CRC in the WVCR-Medicare cohort were relatively younger, predominantly white, lived primarily in nonmetropolitan areas, and belonged mainly to the lower categories of median household income compared to their national counterparts. Those from WVCR-Medicare were sicker and had a higher burden of chronic conditions other than CRC compared to those from the national cohort.
However, fewer beneficiaries from the WVCR-Medicare cohort were diagnosed with regional and distant stage CRC compared to those from the national cohort.

The results from the current study indicated differences in usage of surgery, chemotherapy, and radiation in the 2 populations. West Virginians had lower rates for almost all the CRC treatments/combinations for all cancer site and stage at diagnosis subgroups. Compared to SEERMedicare beneficiaries, WVCR-Medicare also had lower rates for receipt of any surgery as a part of their treatment pattern. 
Table 4. Receipt of Minimally Appropriate Colorectal Cancer Treatment (MACT) among Medicare Beneficiaries with CRC, WVCR-Medicare and SEER-Medicare Cohorts (2003-2006)

\begin{tabular}{|c|c|c|c|c|c|c|}
\hline \multirow[b]{3}{*}{ Variables } & \multicolumn{3}{|c|}{ Proportion received $M A C T$} & \multicolumn{3}{|c|}{ Likelihood of receiving $M A C T$} \\
\hline & \multirow{2}{*}{$\frac{W V C R-M C}{\%}$} & \multirow{2}{*}{$\frac{S E E R-M C}{\%}$} & \multirow[b]{2}{*}{ Sig } & \multicolumn{3}{|c|}{ All } \\
\hline & & & & $A O R$ & $95 \% C I$ & Sig \\
\hline \multicolumn{7}{|l|}{ Cohort } \\
\hline All & 81.83 & 83.98 & $*$ & & & \\
\hline SEER-Medicare & & & & Ref & & \\
\hline WVCR-Medicare & & & & 0.85 & {$[0.76-0.96]$} & $* *$ \\
\hline \multicolumn{7}{|l|}{ Age-group } \\
\hline $66-70$ & 81.88 & 83.70 & & Ref & & \\
\hline $71-75$ & 82.08 & 85.94 & $*$ & 1.13 & [1.04-1.23] & $* *$ \\
\hline $76-80$ & 82.65 & 85.36 & & 1.05 & {$[0.97-1.14]$} & \\
\hline$>80$ & 80.91 & 82.08 & & 0.79 & {$[0.73-0.85]$} & $* * *$ \\
\hline \multicolumn{7}{|l|}{ Sex } \\
\hline Male & 79.76 & 82.52 & $*$ & Ref & & \\
\hline Female & 83.74 & 85.15 & & 1.23 & {$[1.16-1.31]$} & $* * *$ \\
\hline \multicolumn{7}{|l|}{ Race } \\
\hline White & 81.59 & 84.40 & $* * *$ & Ref & & \\
\hline Other & 90.90 & 81.53 & & 0.83 & {$[0.77-0.90]$} & $* * *$ \\
\hline \multicolumn{7}{|c|}{ Charlson comorbidity index score ${ }^{1}$} \\
\hline zero & 81.38 & 84.16 & $*$ & Ref & & \\
\hline 1 or 2 & 81.29 & 83.86 & $*$ & 0.91 & {$[0.86-0.96]$} & $* *$ \\
\hline$\geq 3$ & 85.96 & 83.56 & & 0.87 & {$[0.79-0.97]$} & $*$ \\
\hline \multicolumn{7}{|l|}{ Office visits } \\
\hline Quintile 1 & 75.68 & 80.49 & $*$ & Ref & & \\
\hline Quintile 2 & 78.03 & 84.23 & $* * *$ & 1.31 & {$[1.21-1.42]$} & $* * *$ \\
\hline Quintile 3 & 85.18 & 84.60 & & 1.41 & {$[1.30-1.53]$} & $* * *$ \\
\hline Quintile 4 & 85.02 & 85.47 & & 1.53 & {$[1.40-1.67]$} & $* * *$ \\
\hline Quintile 5 & 84.99 & 85.03 & & 1.52 & [1.39-1.67] & $* * *$ \\
\hline \multicolumn{7}{|l|}{ Metropolitan status } \\
\hline Metro & 80.42 & 84.16 & $* * *$ & Ref & & \\
\hline Nonmetro & 83.18 & 83.07 & & 0.97 & [0.89-1.05] & \\
\hline \multicolumn{7}{|c|}{ Median household income } \\
\hline$\leq \$ 35,000$ & 80.87 & 82.99 & & Ref & & \\
\hline$\$ 36,000-\$ 45,000$ & 82.57 & 83.79 & & 1.04 & [0.97-1.12] & \\
\hline$>\$ 46,000$ & 79.88 & 84.57 & & 1.08 & {$[1.01-1.16]$} & $*$ \\
\hline \multicolumn{7}{|l|}{ Cancer site } \\
\hline Colon & 84.8 & 87.11 & $* *$ & & & \\
\hline Rectal & 72.87 & 73.72 & & & & \\
\hline \multicolumn{7}{|l|}{ Stage at diagnosis } \\
\hline In situ/localized & 78.41 & 80.12 & & & & \\
\hline Regional & 91.63 & 93.65 & $*$ & & & \\
\hline Distant & 72.63 & 75.52 & & & & \\
\hline \multicolumn{7}{|l|}{ Vital status } \\
\hline Alive & 83.87 & 86.78 & $* *$ & & & \\
\hline Dead & 79.25 & 80.76 & & & & \\
\hline
\end{tabular}

Note: Based on 2,119 elderly Medicare beneficiaries with CRC identified from the linked West Virginia Cancer Registry (WVCR)Medicare data and 38,168 beneficiaries identified from the SEER-Medicare data. ${ }^{1}$ Modified Charlson comorbidity index: Deyo-Charlson comorbidity scores, which were calculated for the pre-index 12-month period for each beneficiary and excluded cancer-related comorbidities. Asterisks represent significant group differences by data-source/population using chi-square tests. $* * * P<.001 ; * * .001<$ $P<.01 ; * .01<P<.05$.

$\mathrm{CRC}=$ colorectal cancer; SEER $=$ Surveillance, Epidemiology, and End Results.

On examining the extent of receipt of MACT in the study population, those from WVCR-Medicare were again found to be at a disadvantage compared to their national counterparts. The factors associated with the likelihood of receiving MACT included age, and the total number of office visits. The likelihood of receiving MACT decreased with advancing age, and increased with more interactions with the health care system. Cronnin et al have similarly reported in their study that the receipt of guideline-recommended care declined with increasing age among individuals with 


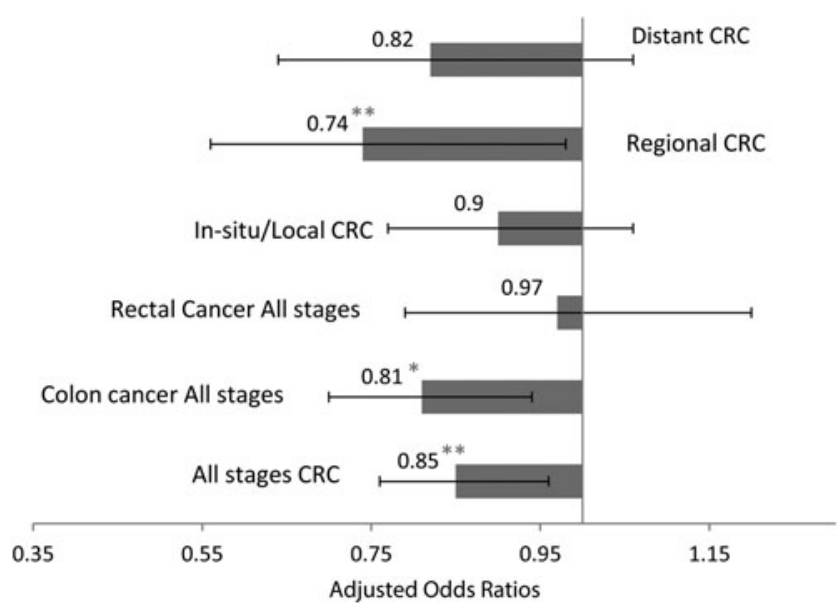

FIG. 1. Adjusted odds ratios depicting the likelihood of receipt of minimally appropriate colorectal cancer treatment among Medicare beneficiaries stratified by cancer stage at diagnosis and by cancer site. WVCR-Medicare and SEERMedicare cohorts (2003-2006).

Note: Based on 2119 elderly Medicare beneficiaries with CRC identified from the linked West Virginia Cancer Registry (WCVR)-Medicare data and 38,168 beneficiaries identified from the SEER-Medicare data.

Asterisks represent significant adjusted odds ratios. $* * *$ $P<.001 ; * * .001<P<.01 ; * .01<P<.05$.

The logistic regression controlled for age, sex, race, CCI number of office visits, metropolitan status, median household income, and the data source/population as independent variables. The SEER-Medicare cohort served as the reference group.

AOR for distant stage $\mathrm{CRC}=0.82 ; 95 \% \mathrm{CI}=[0.64-1.06]$.

AOR for regional stage $\mathrm{CRC}=0.74 ; 95 \% \mathrm{CI}=[0.56-$ 0.98].**

AOR for in-situ/localized stage $\mathrm{CRC}=0.9 ; 95 \% \mathrm{CI}=[0.77-$ 1.06].

AOR for rectal cancer, all stages $=0.97 ; 95 \% \mathrm{CI}=[0.79$ 1.20].

AOR for colon cancer, all stages $=0.81 ; 95 \% \mathrm{CI}=[0.70$ 0.94].*

AOR for $\mathrm{CRC}$, all stages $=0.85 ; 95 \% \mathrm{CI}=[0.76-0.96] . * *$

$\mathrm{AOR}=$ adjusted odds ratio $\mathrm{CCI}=$ Charlson comorbidity index; $\mathrm{CRC}=$ colorectal cancer; $\mathrm{SEER}=$ Surveillance, Epidemiology, and End Results.

CRC. ${ }^{2}$ When stratified by cancer site and stage at diagnosis, it also was found that beneficiaries from WVCR-Medicare diagnosed with regional-stage $\mathrm{CRC}$ and those with all-stage colon cancer were less likely to receive minimally appropriate treatment compared to their national counterparts. As already described, West Virginians also were less likely to receive surgery (which is the mainstay for colon cancer treatment) as a part of their CRC treatment modality compared to their national counterparts. These findings underscore the need for better utilization of the guidelines recommended for $\mathrm{CRC}$ care and for improving access to care, especially surgical therapy, for such rural populations.

The findings from the current study also showed that, for beneficiaries with CRC in the WVCR-Medicare cohort, the important factors associated with CRC-specific mortality included age, comorbidity burden, cancer site and stage at diagnosis, metropolitan status, median household income levels, and the receipt of MACT. Similar to some of the prior CRC studies, mortality rates in this study were higher for those with advancing age, who were sicker, had rectal cancer, were diagnosed at later stages, lived in nonmetropolitan areas, and had lower socioeconomic status. ${ }^{24,25}$ The study results further showed the beneficial effect of receipt of MACT on both all-cause and CRC-specific mortality, similar to the study by Cronnin and colleagues. ${ }^{2}$

Another finding that was observed in the exploratory analysis for this study was that the proportion of beneficiaries with unstaged/unknown stage CRC was higher for beneficiaries from the WVCR-Medicare cohort as compared to those from the national cohort (12.2\% vs 5\%). This could be indicative of some beneficiaries from WV not being staged appropriately for CRC. This could be explained by advancing age, high comorbidity burden (and the leading complex care needs), poor health status, lack of access to facilities with definitive staging services, lower education level, and Appalachian culture in the state, which are some of the factors associated with unknown tumor stage as reported by some studies. ${ }^{26,27}$ This subset of beneficiaries with unstaged CRC possibly end up not receiving appropriate CRC treatment because of missing staging information, which is the most important factor in determining treatment for cancer care. It is unclear if there are certain subgroups in the WVCR-Medicare cohort who were at risk of not being staged for CRC appropriately, and if they contribute to the high CRC mortality because of a lack of appropriate treatment. Thus, further research is needed to unearth the causes of the high proportion of unstaged CRC cases in this rural WV population.

The current study has some limitations, one being that it is based on observational data and therefore cannot establish causality. Data from the WVCR-Medicare linked data set were only available up to year 2009. It will be of great value to observe how the treatment pattern and survival may have changed in this population using updated data from recent years. There are some other limitations that should be considered when interpreting the study results. First, this study included only elderly FFS Medicare beneficiaries aged $\geq 66$ years. Data on beneficiaries from the Medicare-HMO, Medicare-Medicaid dual eligibles, non-Medicaid enrollees, and the uninsured population were not used; thus, the study results may lack generalizability and may not be applicable to other populations. Data on patients' health status and severity of comorbidities were unavailable; these are important factors associated with both the receipt of $\mathrm{CRC}$ treatment and mortality. Finally, this study is also subject to limitations inherent to registry and large claims database studies, such as misclassification and coding errors during claims processing. Despite these limitations, the current study can serve as a good case study to elucidate the receipt of CRC treatment and associated health outcomes in a CRC population that is aging, is sicker, has lower socioeconomic status, and is from a rural setting.

Geographic access to cancer care services has been identified as a barrier to those from rural and medically underserved areas. $^{4,28}$ This study showed that beneficiaries with CRC from a rural setting such as WV are less likely to receive $\mathrm{MACT}$, are less likely to receive any type of $\mathrm{CRC}$ surgery, and also exhibit poor CRC-specific survival compared to their national counterparts. It highlights the need 
Table 5. Relative Risk of Colorectal Cancer-Specific and All-Cause Mortality (36-Month Follow-Up) among Elderly Medicare Beneficiaries with CRC, WVCR and SEER-Medicare Data 2003-2006

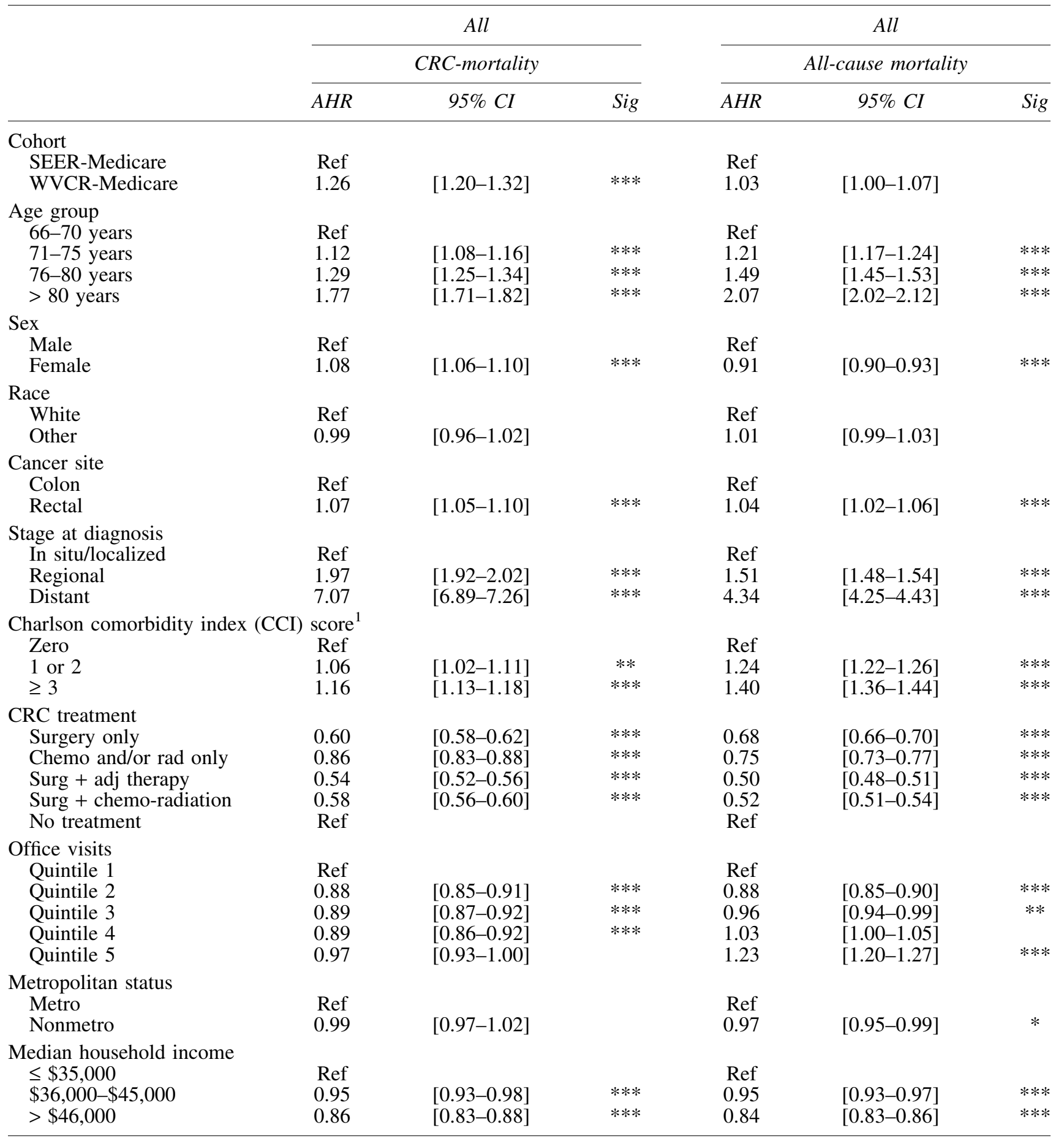

Note: Based on 2119 elderly Medicare beneficiaries diagnosed with CRC in 2002-2003 and identified from the linked West Virginia Cancer Registry (WVCR)-Medicare data and 38,168 beneficiaries identified from the SEER-Medicare data. Beneficiaries were followed for a period of 36 months from the date of cancer diagnosis. Asterisks represent significant adjusted odds ratios. $* * * P<.001 ; * * .001<P<.01$; $* .01<P<.05$. The Cox proportional hazard regression controlled for age, sex, race, cancer site and stage, CCI, number of office visits, metro status, median household income, and the data source/population as independent variables.

In a similar model where CRC treatment patterns were replaced with receipt of MACT:

AHR, CRC-mortality for those who received MACT for WVCR-Medicare group: $0.56,95 \% \mathrm{CI}=[0.50-0.64]$;

AHR, CRC-cause mortality for those who received MACT:0.60, 95\% CI $=[0.59-0.61]$; ref group = no receipt of MACT.

$\mathrm{AHR}=$ adjusted hazards ratio; $\mathrm{CRC}=$ colorectal cancer; $\mathrm{SEER}=$ Surveillance, Epidemiology, and End Results . 
for an increased focus by health care providers and policy makers on improving access to care at every phase of the CRC care continuum, especially for those from rural settings who are vulnerable to poor health outcomes possibly because of a lack of availability of health care resources. Further research needs to be conducted to explore if similar rural-urban differences as observed with WVCR-Medicare beneficiaries persist in CRC treatment receipt and outcomes in the elderly from other rural areas of the nation.

If CRC treatment disparities as observed in WVCRMedicare are similarly observed in other rural areas of the United States, it would highlight the need for policy makers to develop multipronged approaches such as providing patient education, and better care coordination and navigation through the complex cancer care system in rural areas. It also will lead to an increased emphasis on adoption and adherence to accepted surgical and adjuvant treatment guidelines for CRC treatment in all patient populations, including the elderly, those diagnosed at later stages of cancer, and those with a high comorbidity burden.

\section{Author Disclosure Statement}

Drs. Rane, Madhavan, Sambamoorthi, Kurian, and Pan, and Ms. Sita declared no conflicts of interest with respect to the research, authorship, and/or publication of this article.

The authors received the following financial support for this article: This study was funded by the Agency of Healthcare Research and Quality (AHRQ) (Grant \#1-R24 HS018622-01 [PI: S. Madhavan]). The research reported in this article also was partially supported by the National Institute of General Medical Sciences of the National Institutes of Health under Award Number U54GM104942 [PI: S. Hodder]. The opinions expressed and the content are solely the responsibility of the authors and do not necessarily represent the official views of AHRQ or the National Institutes of Health.

\section{Prior Presentation}

A research abstract for this study was presented as a poster at the International Society for Pharmacoeconomics and Outcomes Research (ISPOR) 18th annual international meeting, May 31-June 4, 2014, Montreal, Quebec, Canada.

\section{References}

1. American Cancer Society. Colorectal Cancer Facts \& Figures 2011-2013. Available at: <http://www.cancer.org/ acs/groups/content/@epidemiologysurveilance/documents/ document/acspc-028323.pdf>. Accessed October 5, 2014.

2. Cronin DP, Harlan LC, Potosky AL, Clegg LX, Stevens JL, Mooney MM. Patterns of care for adjuvant therapy in a random population-based sample of patients diagnosed with colorectal cancer. Am J Gastroenterol 2006;101:23082318.

3. Baldwin LM, Cai Y, Larson EH, et al. Access to cancer services for rural colorectal cancer patients. J Rural Health 2008;24:390-399.

4. Byers TE, Wolf HJ, Bauer KR, et al. The impact of socioeconomic status on survival after cancer in the United States: Findings from the National Program of Cancer Registries Patterns of Care Study. Cancer 2008;113:582-591.
5. Haas JS, Brawarsky P, Iyer A, Fitzmaurice GM, Neville BA, Earle C. Association of area sociodemographic characteristics and capacity for treatment with disparities in colorectal cancer care and mortality. Cancer 2011;117: 4267-4276.

6. Hao Y, Jemal A, Zhang X, Ward EM. Trends in colorectal cancer incidence rates by age, race/ethnicity, and indices of access to medical care, 1995-2004 (United States). Cancer Causes Control 2009;20:1855-1863.

7. Onega T, Duell EJ, Shi X, Wang D, Demidenko E, Goodman D. Geographic access to cancer care in the U.S. Cancer 2008;112:909-918.

8. Centers for Disease Control and Prevention. United States Cancer Statistics. 2012 State vs national comparisons: 2009 West Virginia. Available at: <https://nccd.cdc.gov/USCS/ statevsnational.aspx ? Year $=2009 \&$ Variable $1=$ West $\% 20$ Virginia>. Accessed May 15, 2014.

9. United States Census Bureau. State and County QuickFacts, West Virginia. Available at: <http://quickfacts. census.gov/qfd/states/54000.html>. Accessed October 5, 2014.

10. U.S. Department of Health and Human Services, Health Resources and Services Administration. Finding Shortage Areas: Health professionals shortage areas and Medically underserved areas by state, county; 2013. Available at: $<$ http://hpsafind.hrsa.gov/HPSASearch.aspx $>$. Accessed June 6, 2013.

11. West Virginia Bureau for Public Health. West Virginia Healthy People 2010. Available at: <http://www.wvdhhr. org/bph/hp2010/objective/contents.html>. Accessed January 5, 2013.

12. Nadpara P, Madhavan S. Linking Medicare, Medicaid, and cancer registry data to study the burden of cancers in West Virginia. Medicare Medicaid Res Rev 2012;4:E1-E24.

13. Surveillance, Epidemiology, and End Results Program. SEER Registry Groupings for Analyses. Available at: $<$ http://seer.cancer.gov/registries/terms.html>. Accessed May 30, 2013.

14. Warren JL, Klabunde CN, Schrag D, Bach PB, Riley GF. Overview of the SEER-Medicare data: Content, research applications, and generalizability to the United States elderly population. Med Care 2002;40(8 Suppl):IV3-IV-18.

15. Brown ML, Riley GF, Schussler N, Etzioni R. Estimating health care costs related to cancer treatment from SEERMedicare data. Med Care 2002;40(8 Suppl):IV-104-IV117.

16. Riley GF, Potosky AL, Lubitz JD, Kessler LG. Medicare payments from diagnosis to death for elderly cancer patients by stage at diagnosis. Med Care 1995;33:828-841.

17. Taplin SH, Barlow W, Urban N, et al. Stage, age, comorbidity, and direct costs of colon, prostate, and breast cancer care. J Natl Cancer Inst 1995;87:417-426.

18. National Cancer Institute. PDQ ${ }^{\circledR}$ Colon Cancer Treatment. Available at: <http://www.cancer.gov/cancertopics/pdq/ treatment/colon/HealthProfessional/page5>. Accessed February $15,2013$.

19. National Cancer Institute. $P D Q \circledR{ }^{\circledR}$ Rectal Cancer Treatment. Available at: <http://www.cancer.gov/types/colorectal/hp/ rectal-treatment-pdq $>$. Accessed May 30, 2013.

20. Klabunde CN, Legler JM, Warren JL, Baldwin LM, Schrag D. A refined comorbidity measurement algorithm for claims-based studies of breast, prostate, colorectal, and lung cancer patients. Ann Epidemiol 2007;17:584-590. 
21. Choi JY, Chang YJ, Hong YS, et al. Complementary and alternative medicine use among cancer patients at the end of life: Korean national study. Asian Pac J Cancer Prev 2012;13:1419-1424.

22. Hadley J, Yabroff KR, Barrett MJ, Penson DF, Saigal CS, Potosky AL. Comparative effectiveness of prostate cancer treatments: Evaluating statistical adjustments for confounding in observational data. J Natl Cancer Inst 2010; 102:1780-1793.

23. Koo DH, Yun SC, Hong YS, et al. Systemic chemotherapy for treatment of advanced small bowel adenocarcinoma with prognostic factor analysis: Retrospective study. BMC Cancer 2011;11:205.

24. Chang GJ, Skibber JM, Feig BW, Rodriguez-Bigas M. Are we undertreating rectal cancer in the elderly? An epidemiologic study. Ann Surg 2007;246:215-221.

25. Lang K, Korn JR, Lee DW, Lines LM, Earle CC, Menzin J. Factors associated with improved survival among older colorectal cancer patients in the US: A population-based analysis. BMC Cancer 2009;9:227.

26. Merrill RM, Sloan A, Anderson AE, Ryker K. Unstaged cancer in the United States: A population-based study. BMC Cancer 2011;11:402.

27. Kurkjian C, Kummar S. Advances in the treatment of metastatic colorectal cancer. Am J Ther 2009;16:412-420.

28. Etzioni DA, El-Khoueiry AB, Beart RW Jr. Rates and predictors of chemotherapy use for stage III colon cancer: A systematic review. Cancer 2008;113:3279-3289.

Address correspondence to: Dr. Pallavi B. Rane 3805 Lupine Ln, Apt. $M$ Calabasas, CA 91302

E-mail: Pallavibrane@gmail.com 